\title{
Empagliflozin in Type 2 Diabetes Mellitus Patients with High Cardiovascular Risk: A Model-Based Cost-Utility Analysis in China
}

This article was published in the following Dove Press journal: Diabetes, Metabolic Syndrome and Obesity: Targets and Therapy

\author{
Peng Men ${ }^{1,2}$ \\ Tianbi Liu ${ }^{1,3}$ \\ Suodi Zhai ${ }^{1,2}$ \\ 'Department of Pharmacy, Peking \\ University Third Hospital, Beijing, \\ People's Republic of China; ${ }^{2}$ Institute for \\ Drug Evaluation, Peking University Health \\ Science Center, Beijing, People's Republic \\ of China; ${ }^{3}$ Department of Pharmacy \\ Administration and Clinical Pharmacy, \\ School of Pharmaceutical Sciences, Peking \\ University, Beijing, People's Republic of \\ China
}

Correspondence: Suodi Zhai Department of Pharmacy, Peking University Third Hospital, No. 49 North Huayuan Road, Haidian District, Beijing, People's Republic of China

Tel +86-|340|I69|43

Fax+86-10-82266686

Email zhaisuodi@I63.com
Purpose: To evaluate the cost-utility of empagliflozin, in addition to best available standard care (BASC), for the treatment of adult patients with T2DM at high cardiovascular risk from the Chinese healthcare system perspective.

Methods: A Microsoft Excel-based patient-level simulation model, based on the EMPAREG OUTCOME trial data, was adapted and used to project individual's clinical and economic outcomes over a lifetime horizon. The cost and utility values were derived from databases and published studies. Numbers and rates of diabetes-related events, life-years (LYs), quality-adjusted life-years (QALYs), costs (¥ 2019) as well as incremental cost-utility ratios (ICURs) were calculated. Deterministic and probabilistic sensitivity analyses were conducted to test the robustness of the model results.

Results: Compared with BASC, empagliflozin plus BASC was predicted to result in an additional 1.01 QALYs (8.05 QALYs vs 7.04 QALYs) at an incremental cost of $¥ 4002$ per patient. The modeled ICUR was $¥ 3988$ per QALY gained, which was considered highly cost-effective in China compared to both one and three times the GDP per capita in 2019 ( $¥ 70,892$ and $¥ 212,676$ ). The deterministic and probabilistic sensitivity analyses confirmed the robustness of base-case results.

Conclusion: This is the first cost-utility analysis regarding the use of empagliflozin in patients with T2DM in China, the world's most affected country by the T2DM pandemic. The economic evaluation suggests that empagliflozin added to BASC was estimated to be a highly value-for-money option for the treatment of adult patients with T2DM at high cardiovascular risk in the Chinese healthcare setting.

Keywords: diabetes, China, sodium-glucose transporter 2 inhibitors, cost-effectiveness

\section{Introduction}

Type 2 diabetes mellitus (T2DM) is increasingly becoming a global burden, accounting for about $90 \%$ of all diabetes cases. ${ }^{1}$ The prevalence of diabetes in China is the highest worldwide (116.4 million), with an estimated T2DM prevalence of $10.4 \%$ in the adult population. ${ }^{2}$ There is well-established evidence that T2DM is frequently associated with increased cardiovascular risk. ${ }^{3-5}$ The presence of both T2DM and cardiovascular disease significantly increases mortality risk. ${ }^{6}$ Although maintaining controlled blood glucose levels may lower the risk of T2DMrelated cardiovascular events and kidney disease, ${ }^{7,8}$ previous studies had not presented a definite association between traditional pharmacotherapy and benefits on cardiovascular risk, ${ }^{9,10}$ let alone some anti-glycemic agents (such as rosiglitazone) have been associated with increased cardiovascular morbidity and mortality. ${ }^{11}$ 
Sodium-glucose co-transporter 2 (SGLT-2) inhibitors are able to lower blood glucose hemoglobin Alc (HbA1c) through increasing urinary glucose excretion by lowering the renal threshold for glucose. ${ }^{12-15}$ Empagliflozin is a selective SGLT-2 inhibitor that has been approved for $\mathrm{HbAlc}$ management in patients with T2DM and is associated with weight loss and systolic blood pressure (SBP) reduction. The EMPA-REG OUTCOME trial examined the effects of empagliflozin versus placebo on cardiovascular morbidity and mortality in patients with T2DM at high cardiovascular risk who were receiving the best available standard care (BASC), which consisted of glucose-lowering treatment(s) according to local guidelines. ${ }^{16}$ This trial showed significantly lower rates of cardiovascular outcomes and mortality with the addition of empagliflozin.

Empagliflozin has been listed in the National Reimbursement Drug List in late 2019, three years after approved by Chinese National Medicinal Products Administration (Chinese FDA). Due to the relatively higher prices than other conventional oral antidiabetic drugs, treatments with SGLT-2 inhibitors like empagliflozin may impose a potential economic impact on healthcare payers, despite its benefits. Previous research articles have examined the pharmacoeconomic profiles of empagliflozin in the USA, UK, Greece and Japan, using Markov model or discrete event simulation model ${ }^{17-20}$ However, these results could not be transferred to other countries due to the significant differences of costs and health systems among countries. Currently, there was no model-based pharmacoeconomic analysis of empagliflozin in China, and also no published real-world study around the effectiveness and/or cost-effectiveness of empagliflozin. The objective of this study was to evaluate the cost-utility of empagliflozin, in addition to BASC, for the treatment of adult patients with T2DM at high cardiovascular risk from the Chinese healthcare system perspective.

\section{Methods}

\section{Patient Populations}

Baseline patient characteristic profiles were retrieved from the patient-level data of the EMPA-REG OUTCOME trial (Table 1), which was performed in accordance with the principles of the Declaration of Helsinki and the International Conference on Harmonization Good Clinical Practice guidelines and was approved by local authorities of the participating trial sites. ${ }^{16}$ The specific
Table I Population Characteristics

\begin{tabular}{|l|l|}
\hline Population Parameter & Value \\
\hline Age (years) & 63 \\
Sex (female, \%) & $28 \%$ \\
BMI $\geq 30 \mathrm{~kg} / \mathrm{m}^{2}(\%)$ & $52 \%$ \\
$\mathrm{HbAlc} \geq 8.5 \%(\%)$ & $31 \%$ \\
History of stroke (\%) & $24 \%$ \\
History of myocardial infarction (\%) & $46 \%$ \\
History of peripheral artery disease (\%) & $20 \%$ \\
History of coronary artery bypass grafting (\%) & $24 \%$ \\
History of multi-vessel coronary artery disease (\%) & $47 \%$ \\
History of single-vessel coronary artery disease (\%) & $10 \%$ \\
eGFR between 60 and $90 \mathrm{~mL} /$ min (\%) & $53 \%$ \\
eGFR <60 mL/min (\%) & $26 \%$ \\
\hline
\end{tabular}

Abbreviations: BMI, body mass index; HbAlc, hemoglobin Alc; eGFR, estimated glomerular filtration rate.

population was adult patients with T2DM with high cardiovascular risk (established cardiovascular disease) and with a body-mass index (BMI) $\leq 45 \mathrm{~kg} / \mathrm{m}^{2}$ and an estimated glomerular filtration rate (eGFR) of at least $30 \mathrm{~mL} /$ $\min / 1.73 \mathrm{~m}^{2}$ of body-surface area.

\section{Model Structure}

A Microsoft Excel-based patient-level simulation model has been used to assess the pharmacoeconomic profiles of empagliflozin in several other countries. ${ }^{18-20}$ In this study, the model was adapted to the Chinese setting and applied to determine the cost-utility of empagliflozin versus placebo on top of BASC over a lifetime horizon, from the perspective of Chinese healthcare payer. A total of 5000 patients that randomly sampled from the EMPA-REG OUTCOME trial were simulated for base-case analysis. The overall model structure is shown in Figure 1. The model began with the creation of simulated patient profiles. Each profile was cloned and one clone for each patient was assigned to each comparator (empagliflozin and placebo). Next, predicted time to event was assigned for each of the vital clinical events based on statistical extrapolations of event rates from EMPA-REG OUTCOME trial. For each simulated patient, the earliest event was determined and this was the one that is considered to occur. Once this event had been selected, the current time was assigned, and the simulation clock was updated to the occurrence time of the event. If that event was the end of the model time horizon or death, the cumulative event, cost, life-year (LY) and qualityadjusted life-year (QALY) results for the patient were stored and the model moved to the next patient. If not, 


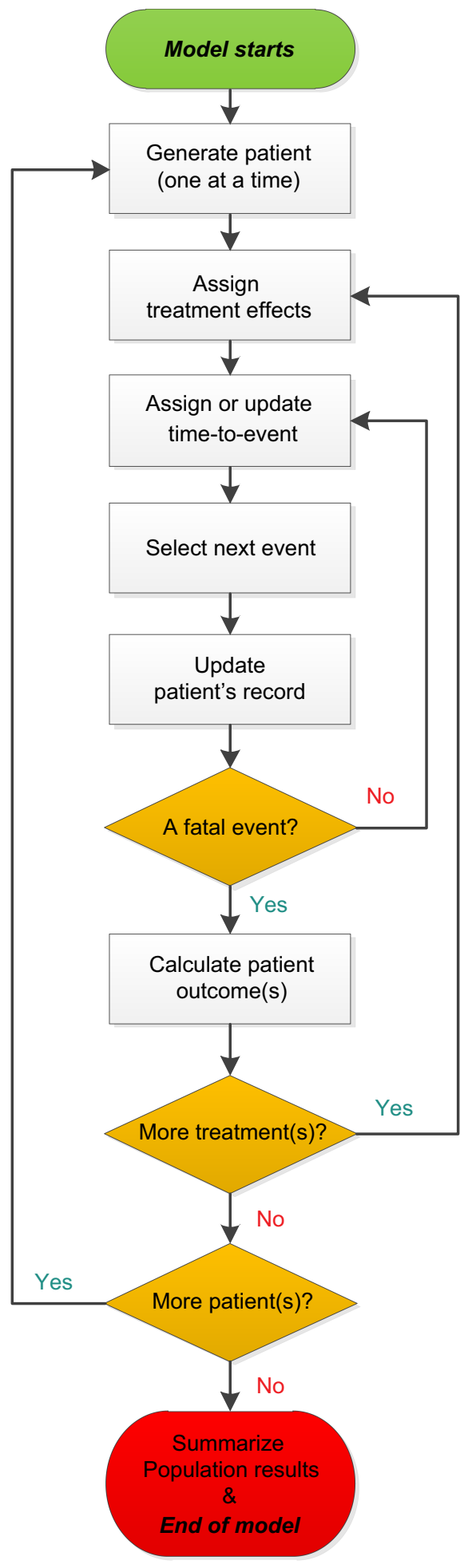

Figure I Diagram of the simulation model process.

both the risk of future events and the predicted times to event were updated. The earliest event was again selected and the process repeated until a fatal event was experienced. As events accumulate, each simulated patient can alter the risk of future events. The background mortality was obtained from the Chinese life expectancy tables of the World Health Organization's (WHO) member states. Once all patients had been simulated on both treatments, the results were summed to compute the overall results.

\section{Clinical Events and Utility Inputs}

There were 11 vital clinical events that included in the model: cardiovascular death, (hospitalization for) heart failure, macro-albuminuria, non-fatal myocardial infarction (MI), non-fatal stroke, non-cardiovascular death, renal injury (defined as a doubling of serum creatinine, with eGFR $<45 \mathrm{~mL} / \mathrm{min} / 1.73 \mathrm{~m}^{2}$ ), renal transplantation, revascularization, transient ischemic attack (TIA) and unstable angina. Note that some very rare complications were not included in the model since these events were too rare to be captured in the EMPA-REG OUTCOME trial. Microvascular complications have been shown to be predicted by changes in $\mathrm{HbAlc}$, which was similar across the treatment arms, limiting the incremental effect these events might have. Clinical event rates were derived from endpoints specified in the EMPA-REG OUTCOME trial by fitting time-dependent parametric survival functions. The best fitting parametric distribution was identified for each outcome. Then, potential baseline and time-dependent predictors of the events were tested to multivariate parametric survival functions. The model also has the ability to scale the rates of each event type by a constant hazard ratio (HR). Each event type has a separate HR that applies over the entire time horizon.

Patient quality of life was determined using a baseline value and a permanent decrement associated with the history of each event experienced. Since China-specific utilities were currently not available, a utility study that was previously used in pharmacoeconomic analyses of T2DM management across countries (including China) was applied. ${ }^{21}$ The study provides a fixed decrement in utility for each event type along with a rule for combining decrements as patients accumulate multiple diabetes-related complicating conditions. The baseline utility, event decrements, and combining rules are shown in Table 2.

\section{Cost Inputs}

Drug acquisition costs and costs associated with clinical events were included in the analysis, all from the perspective of the Chinese healthcare payer. All cost inputs reflected the year 2019 Chinese Yuan (CNY, ¥). Drug acquisition costs for empagliflozin were obtained from the DRUGDATAEXPY (Chinese phonetic alphabet: Yao 
Table 2 The Baseline Utility, Event Decrements, and Combining Rules Used in the Model

\begin{tabular}{|l|l|l|}
\hline Event & Utility & SE \\
\hline Baseline value & & \\
$\quad$ Mean patient characteristics & 0.785 & \\
\hline Event decrements & & \\
Heart failure & -0.05 & 0.007 \\
Macro-albuminuria & -0.038 & 0.011 \\
Non-fatal myocardial infarction & -0.047 & 0.005 \\
Non-fatal stroke & -0.06 & 0.007 \\
Renal injury & -0.038 & 0.011 \\
Renal transplantation & -0.038 & 0.011 \\
Revascularization & -0.03 & - \\
Transient ischemic attack & -0.07 & 0.31 \\
Unstable angina & -0.047 & 0.005 \\
\hline Effect of multiple events (additive to utility) & & \\
2 events & 0.017 & 0.007 \\
3 events & 0.042 & 0.012 \\
4 events & 0.070 & 0.017 \\
5 or more events & 0.087 & 0.022 \\
\hline
\end{tabular}

Abbreviation: SE, standard error.

Zhi) database. Because empagliflozin was compared against placebo in EMPA-REG OUTCOME trial, no other costs for antidiabetic drugs were considered. This was an assumption that favoring placebo as more patients intensified their anti-diabetic treatments in order to maintain glucose control, according to the trial sponsor. The costs of anti-hypertensive drugs, lipidlowering drugs and anti-coagulants were also not included in the analysis since the proportions of patients receiving these agents were similar between empagliflozin and placebo groups.

Costs associated with clinical events were based on published China-based studies and validated by local clinician expert(s). ${ }^{22-27}$ Retrieved costs were inflated to 2019 CNY according to the consumer price index, if necessary. ${ }^{28}$ See Table 3 for further details on drug acquisition costs and event-associated costs. Costs of long-term event management were not included in the analysis to prevent the risk of double-counting future event costs.

\section{Cost-Utility Analysis}

The cost-utility of empagliflozin was evaluated by calculating the incremental cost per QALY gained, ie, the incremental cost-utility ratio (ICUR). Costs and QALYs were discounted at a $3.5 \%$ annual rate in the
Table 3 Costs of Drugs and Clinical Events

\begin{tabular}{|c|c|c|c|}
\hline Items & Cost (¥) & SE & Source \\
\hline \multicolumn{4}{|l|}{ Drug acquisition costs } \\
\hline Empagliflozin & 4.24 & - & DRUGDATAEXPY \\
\hline BASC & 0.00 & - & - \\
\hline \multicolumn{4}{|l|}{$\begin{array}{l}\text { Costs associated with each } \\
\text { clinical event (per episode) }\end{array}$} \\
\hline Cardiovascular death & 33,185 & 8079 & Zheng et $\mathrm{al}^{14}$ \\
\hline Heart failure & 23,270 & 2733 & Zheng et $\mathrm{al}^{14}$ \\
\hline Macro-albuminuria & 42,736 & - & Wang et $\mathrm{al}^{15}$ \\
\hline Non-cardiovascular death & 13,513 & - & Xie et al $^{16}$ \\
\hline $\begin{array}{l}\text { Non-fatal myocardial } \\
\text { infarction }\end{array}$ & 40,668 & 4732 & Zheng et $\mathrm{al}^{14}$ \\
\hline Non-fatal stroke & 23,680 & 2083 & Zheng et $\mathrm{al}^{14}$ \\
\hline Renal injury & 30,046 & - & Fang et $\mathrm{al}^{17}$ \\
\hline Renal transplantation & 487,866 & 210,576 & Zheng et $\mathrm{al}^{14}$ \\
\hline Revascularization & 59,293 & - & Chen et $\mathrm{al}^{18}$ \\
\hline Transient ischemic attack & 10,510 & - & Zhang et al $^{19}$ \\
\hline Unstable angina & 30,881 & 4120 & Zheng et $\mathrm{al}^{14}$ \\
\hline
\end{tabular}

Abbreviations: SE, standard error; BASC, standard of care.

base case, while event counts and life years were not discounted.

As there is no documentation on the willingness to pay (WTP) for a QALY gained in China, one and three times the current annual gross domestic product (GDP) per capita that recommended by the Commission on Macroeconomics and Health of the WHO were both used as WTPs in this study. ${ }^{29}$ The WTPs were, therefore, $¥ 70,892$ and $¥ 212,676$ per QALY. $^{30}$

A series of deterministic sensitivity analyses (DSA) were performed. Inputs including time horizon, discount rate, cost inputs and utility inputs were examined, respectively. Probabilistic sensitivity analysis (PSA) was also run using 1000 replications for 5000 individual patients in order to generate relatively broader $95 \%$ confidence intervals (CIs) around event rates and ICUR in both arms. Probability distributions (gamma and beta) were attached, respectively, to event costs and utilities for running secondorder Monte Carlo simulations.

\section{Results \\ Base-Case Analysis}

The results of the base-case analysis showed that empagliflozin plus BASC was predicted to result in longer mean survivals (14.75 LYs vs 12.36 LYs), compared with BASC alone. Also, patients under the treatment of empagliflozin were associated with reduced rates of 
Table 4 Base Case Analysis Results

\begin{tabular}{|c|c|c|c|}
\hline Results & Empagliflozin + BASC & BASC & Net Differences \\
\hline \multicolumn{4}{|l|}{ Results of clinical events (per 100 patient-years) } \\
\hline Cardiovascular death & 4.11 & 5.78 & -1.67 \\
\hline Heart failure & 2.08 & 3.11 & -1.03 \\
\hline Macro-albuminuria & 5.24 & 6.39 & -1.15 \\
\hline Non-cardiovascular death & 2.67 & 2.31 & 0.36 \\
\hline Non-fatal myocardial infarction & 1.94 & 2.20 & -0.26 \\
\hline Non-fatal stroke & 1.36 & 1.09 & 0.27 \\
\hline Renal injury & 1.02 & 1.56 & -0.54 \\
\hline Renal transplantation & 0.33 & 0.56 & -0.23 \\
\hline Revascularization & 2.67 & 2.91 & -0.24 \\
\hline Transient ischemic attack & 0.26 & 0.31 & -0.04 \\
\hline Unstable angina & 1.33 & 1.26 & 0.06 \\
\hline \multicolumn{4}{|l|}{ Results of the incremental cost-utility ratio } \\
\hline Undiscounted LYs per patient & 14.75 & 12.36 & 2.39 \\
\hline Discounted QALYs per patient & 8.05 & 7.04 & 1.01 \\
\hline Drug acquisition cost per patient ( $¥)$ & 16,567 & 0 & 16,567 \\
\hline Event management cost per patient $(¥)$ & 99,425 & 111,990 & $-12,565$ \\
\hline Total costs per patient per patient $(¥)$ & 115,992 & 111,990 & 4002 \\
\hline ICUR (¥/QALY) & 3988 & & \\
\hline
\end{tabular}

Abbreviations: ICUR, incremental cost-utility ratio; LY, life-year; BASC, best available standard care; QALY, quality-adjusted life-year.

clinical events, including cardiovascular death (4.11 vs 5.78, per 100 patient-years), heart failure ( 2.08 vs 3.11 ), nonfatal myocardial infarction (1.94 vs 2.20), renal injury (1.02 vs 1.56$)$ and renal transplantation ( 0.33 vs $0.56)$. The predicted burden of illness, costs of care and benefits of cardiovascular event risk reduction are listed in Table 4.

This resulted in a predicted additional 1.01 QALYs with empagliflozin (8.05 QALYs vs 7.04 QALYs with BASC) at an incremental cost of $¥ 4002$ per patient. Empagliflozin was considered highly cost-effective in China, given the generated ICUR ( $¥ 3988$ per QALY gained), which was lower than both one and three times the GDP per capita in 2019.

\section{Sensitivity Analyses}

The base-case results were robust to changes in the model parameters and in the assumptions underlying the DSA. None of the results exceeded one time the GDP per capita. Relatively strong drivers of ICUR included time horizon, discount rate (of costs), and empagliflozin drug cost. The results of deterministic sensitivity analysis are presented in Table 5 .

The PSA (1000 replications of 5000 patients each) resulted in relatively broad $95 \%$ CIs around event rates in both arms (Table 6). The PSA confirmed the base-case results generating an ICUR of $¥ 2820$ (95\% CI: $¥-20,384$ to
$¥ 18,485$, Figure 2). At GDP per capita in 2019 (¥70,892), empagliflozin had a $100 \%$ probability of being highly costeffective.

Table 5 Results of Deterministic Sensitivity Analysis

\begin{tabular}{|l|l|l|}
\hline Main Parameters & Input & ICUR (¥/QALY) \\
\hline Model setup & 10 years & $-16,570$ \\
\hline Time horizon & $0 \%$ & 12,340 \\
\hline Discount rate: cost & $5 \%$ & 2076 \\
\hline Discount rate: health & $0 \%$ & 1675 \\
& $5 \%$ & 4968 \\
\hline Discount rate: cost and health & $0 \%$ & 5182 \\
& $5 \%$ & 2586 \\
\hline Cost inputs & \multicolumn{2}{|l|}{} \\
\hline Empagliflozin cost & $20 \%$ decrease & 686 \\
& $20 \%$ increase & 7290 \\
\hline Event cost & $20 \%$ decrease & 6813 \\
& $20 \%$ increase & 1964 \\
\hline Utility inputs & $20 \%$ decrease & 5045 \\
\hline Utility, no event history & $20 \%$ increase & 3298 \\
\hline Utility decrement & $20 \%$ decrease & 3937 \\
& $20 \%$ increase & 4041 \\
\hline
\end{tabular}

Abbreviations: ICUR, incremental cost-utility ratio; QALY, quality-adjusted life-year. 
Table 6 Event Rates and Outcomes in the PSA

\begin{tabular}{|c|c|c|}
\hline Results & Empagliflozin + BASC & BASC \\
\hline \multicolumn{3}{|l|}{ Event-rate per 100 -patient years } \\
\hline Cardiovascular death & $4.19(3.55,5.05)$ & $5.89(5.09,6.99)$ \\
\hline Heart failure & $2.18(1.59,3.00)$ & $3.23(2.36,4.38)$ \\
\hline Macro-albuminuria & $5.26(4.79,5.79)$ & $6.4 \mathrm{I}(5.82,7.05)$ \\
\hline Non-cardiovascular death & $2.66(2.43,2.84)$ & $2.30(2.11,2.48)$ \\
\hline Non-fatal myocardial infarction & $1.99(I .62,2.4 I)$ & $2.29(1.84,2.84)$ \\
\hline Non-fatal stroke & $\mathrm{I} .47(\mathrm{I} .10,2.0 \mathrm{I})$ & I.18 (0.85 I.73) \\
\hline Renal injury & $1.02(0.79,1.28)$ & $1.58(1.26,1.98)$ \\
\hline Renal transplantation & $0.37(0.19,0.63)$ & $0.62(0.35,0.97)$ \\
\hline Revascularization & $2.70(2.50,2.90)$ & $2.95(2.65,3.25)$ \\
\hline Transient ischemic attack & $0.30(0.21,0.42)$ & $0.34(0.2 \mathrm{I}, 0.5 \mathrm{I})$ \\
\hline Unstable angina & $1.38(1.08,1.80)$ & $1.31(0.98,1.78)$ \\
\hline \multicolumn{3}{|l|}{ Outcome per patient } \\
\hline LYs & $14.6 \mid(13.29,15.61)$ & $12.24(10.95,13.21)$ \\
\hline QALYs & $7.98(7.50,8.36)$ & $6.98(6.46,7.39)$ \\
\hline Costs & $1 \mid 8,252(|02,4| 8,|44,0| 4)$ & $115,297(92,965,149,718)$ \\
\hline
\end{tabular}

Abbreviations: ICUR, incremental cost-utility ratio; LY, life-year; PSA, probabilistic sensitivity analysis; BASC, best available standard care; QALY, quality-adjusted life-year.

\section{Discussion}

This is the first cost-utility analysis regarding the use of empagliflozin in patients with T2DM in China, the world's most affected country by the T2DM pandemic. With the base-case settings employed in the model, empagliflozin plus BASC was found to be highly cost-effective compared to BASC with an ICUR of $¥ 3988$ per QALY gained. Empagliflozin was demonstrated to reduce incidence rates of cardiovascular clinical events compared with BASC, which resulted in greater improvements in both life expectancy and quality-adjusted life expectancy. Although the costs of empagliflozin therapy were found to be more costly compared to BASC, mainly due to the additive drug acquisition costs of this SGLT-2 inhibitor, they were offset by the significant clinical and patient-level benefits. This cost-utility estimate was stable in both DSA and PSA,

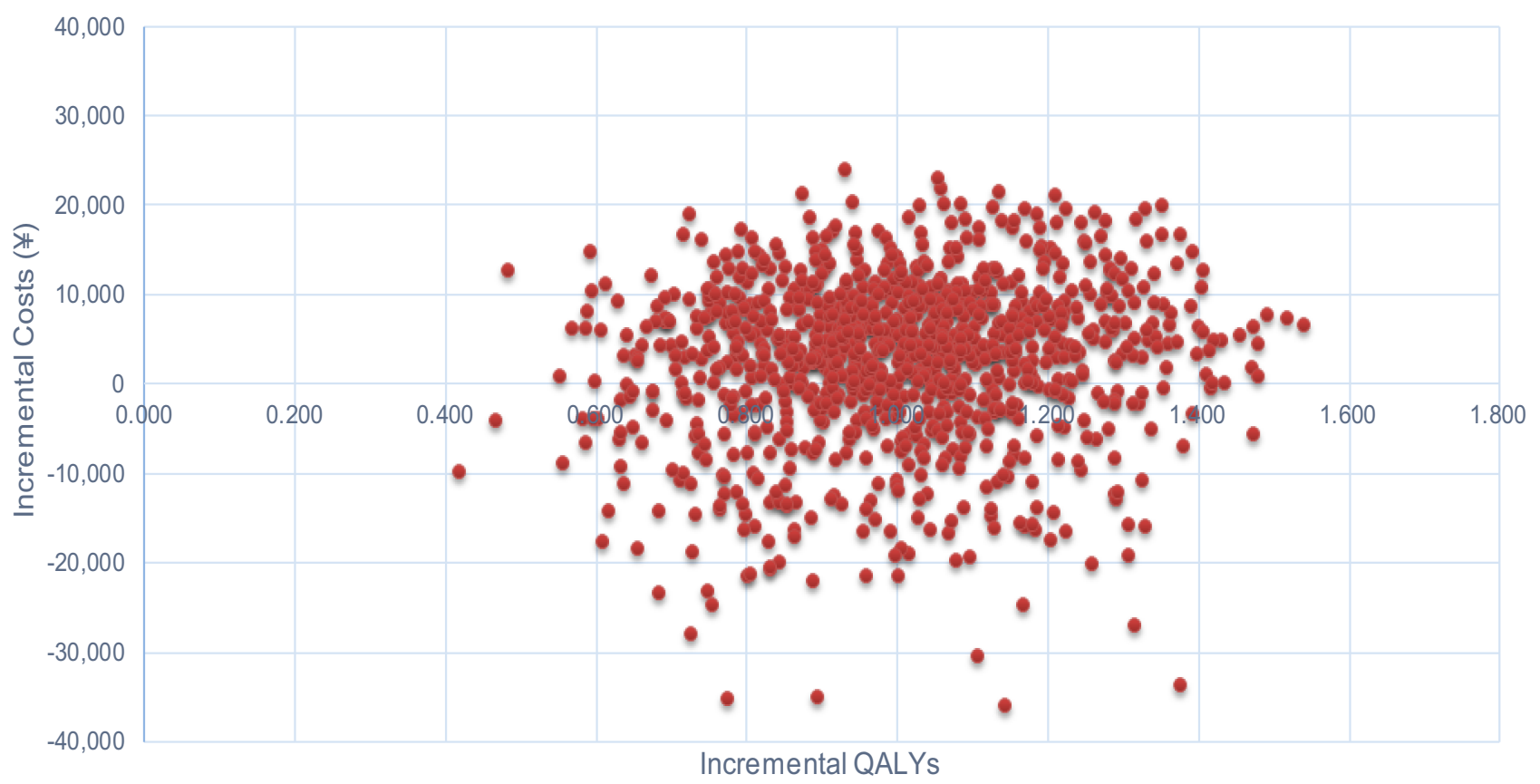

Figure 2 Scatterplot of incremental QALY versus incremental costs. Notes: QALY, quality-adjusted life-year. 
with a $95 \%$ CI ranging from $¥-20,384$ to $¥ 18,485$ in the PSA, indicating the potential of empagliflozin to be costsaving. The stability of these results is driven by the importance of reduced main adverse cardiovascular event rates, which were highly significant in the EMPA-REG OUTCOME trial. The model relied exclusively on the EMPA-REG OUTCOME study data to predict event rates, without including any risk equations based on surrogate biomarkers. The time to event approach allowed for the direct utilization of endpoints data from the trial in the cost-utility analyses. The time-dependent regression functions generated from the trial have also been validated by comparing actual events in the trial with 3-year calculated results. $^{31}$

A recent systematic review summarized all the available evidence regarding the pharmacoeconomic profiles of SGLT2 inhibitors. $^{32}$ The results showed that available SGLT-2 inhibitors were cost-effective treatments compared to other oral antiglycemic drugs and insulin in the treatment of uncontrolled T2DM patients, making them good choices in high cardiovascular risk individuals. Several studies and conference abstracts reported the cost-effectiveness/utility of empagliflozin, across the perspective of payers in several countries, as monotherapy, dual or triple therapy, or in comparison to the standard of care in individuals with T2DM. ${ }^{17-}$ 20,33-38 A majority of these studies analyzed data from EMPA-REG OUTCOME trial. The results consistently demonstrated that treatment with empagliflozin was found to be cost-effective compared to the BASC treatment in individuals with T2DM and cardiovascular disease. To be noted, some studies examined the cost-effectiveness/utility of empagliflozin to the other SGLT-2 inhibitors with a background of double or triple therapy, from which empagliflozin was found to be cost-effective than either dapagliflozin or canagliflozin. ${ }^{39-41}$ Moreover, some researchers focused on the comparisons between SGLT-2 inhibitors and other drug classes and demonstrated empagliflozin was more cost-effective than sitagliptin and liraglutide. ${ }^{42,43}$ Some other studies focused on the similar issue; however, these analyses were either based on indirect model (the IQVIA CORE model uses HbA1c, blood glucose level and BMI as key model inputs, rather than direct cardiovascular outcomes) ${ }^{44}$ or with a short time-horizon (1 year). ${ }^{44}$

Currently, SGLT-2 inhibitors (with benefit evidence, including empagliflozin) have been recommended by both American Diabetes Association (ADA) and European Society of Cardiology (ESC)/European Association for the Study of Diabetes (EASD) guidelines ${ }^{45,46}$ as part of the glucose-lowering regimen independent of $\mathrm{HbAlc}$ among T2DM patients who have established atherosclerotic cardiovascular disease or indicators of high risk, established kidney disease, or heart failure. However, in Chinese Diabetes Society guideline, ${ }^{47}$ SGLT-2 inhibitors were still recommended as one of the second-line choices for T2DM patients inadequately controlled by first-line drugs. This evidence highlights the value for money of the clinical use and reimbursement for empagliflozin, and supports the practicability of listing empagliflozin as one of the first-line options for T2DM patients at high cardiovascular risk in the future Chinese T2DM guideline.

The model has been established with the currently best available data and assumptions; however, there are still limitations to be acknowledged. First of all, the model was conservative in the modeling of treatment, assuming no difference in the costs of treatment between arms other than the presence of empagliflozin and that empagliflozin was never discontinued. This may lead to an underestimation of empagliflozin as more patients in the BASC group received necessarily intensified glucose-lowering treatment, according to the EMPA-REG OUTCOME study. Secondly, the model was not able to involve other T2DM-related complications in the cost-utility analysis. The overall directionality of disinvolving these events cannot be determined a priori. Thirdly, the utility data were not Chinese-specific, since currently there is no credible utility study on Chinese T2DM patients. We have applied the best data available to the analysis.

In summary, this economic evaluation suggests that empagliflozin added to BASC was estimated to be a highly value-for-money option for the treatment of adult patients with T2DM at high cardiovascular risk in a Chinese healthcare setting.

\section{Data Sharing Statement}

The datasets generated during and/or analyzed during the current study are available from the corresponding author on reasonable request.

\section{Compliance with Ethics Guidelines}

This article is based on previously conducted studies and does not contain any studies with human participants or animals performed by any of the authors.

\section{Author contributions}

All authors made substantial contributions to conception and design, acquisition of data, or analysis and interpretation of 
data; took part in drafting the article or revising it critically for important intellectual content; agreed to submit to the current journal; gave final approval of the version to be published; and agree to be accountable for all aspects of the work.

\section{Funding}

This study was funded by Boehringer Ingelheim (China) Investment Co., Ltd.

\section{Disclosure}

None of the authors has any personal or financial conflict of interest.

\section{References}

1. Saeedi P, Petersohn I, Salpea P, et al. Global and regional diabetes prevalence estimates for 2019 and projections for 2030 and 2045: results from the International Diabetes Federation Diabetes Atlas, 9th edition. Diabetes Res Clin Pract. 2019;157:107843. doi:10.1016/j. diabres.2019.107843

2. Xu Y, Wang L, He J, et al. Prevalence and control of diabetes in Chinese adults. JAMA. 2013;310:948-959. doi:10.1001/jama.2013.168118

3. Sarwar N, Gao P, Gobin R, et al. Diabetes mellitus, fasting blood glucose concentration, and risk of vascular disease: a collaborative meta-analysis of 102 prospective studies. Lancet. 375;2010: 2215-2222. doi:10.1016/S0140-6736(10)60484-9

4. Rao Kondapally Seshasai S, Kaptoge S, Thompson A, et al. Diabetes mellitus, fasting glucose, and risk of cause-specific death. $N$ Engl J Med. 2011;364:829-841.

5. Bancks MP, Ning H, Allen NB, et al. Long-term absolute risk for cardiovascular disease stratified by fasting glucose level. Diabetes Care. 2019;42:457-465. doi:10.2337/dc18-1773

6. Di Angelantonio E, Kaptoge S, Wormser D; Emerging Risk Factors Collaboration, et al. Association of cardiometabolic multimorbidity with mortality. JAMA. 314;2015:52-60. doi:10.1001/jama.2015.7008

7. ADVANCE Collaborative Group. Intensive blood glucose control and vascular outcomes in patients with type 2 diabetes. $N$ Engl J Med. 2008;358:2560-2572.

8. Stratton IM, Adler AI, Neil HA, et al. Association of glycaemia with macrovascular and microvascular complications of type 2 diabetes (UKPDS 35): prospective observational study. BMJ. 2000;321 (7258):405-412. doi:10.1136/bmj.321.7258.405

9. Kassem SA, Raz I. Is there evidence that oral hypoglycemic agents reduce cardiovascular morbidity or mortality? No. Diabetes Care. 2009;32(Suppl 2):S337-S341. doi:10.2337/dc09-S335

10. Bianchi C, Miccoli R, Daniele G, Penno G, Del Prato S. Is there evidence that oral hypoglycemic agents reduce cardiovascular morbidity/mortality? Yes. Diabetes Care. 2009;32(Suppl 2):S342-S348. doi:10.2337/dc09-S336

11. Nissen SE, Wolski K. Effect of rosiglitazone on the risk of myocardial infarction and death from cardiovascular causes. $N$ Engl $J$ Med. 2007;356:2457-2471. doi:10.1056/NEJMoa072761

12. Bailey CJ. Renal glucose reabsorption inhibitors to treat diabetes. Trends Pharmacol Sci. 2011;32:63-71. doi:10.1016/j.tips.2010.11.011

13. Chao EC, Henry RR. SGLT2 inhibition - a novel strategy for diabetes treatment. Nat Rev Drug Discov. 2010;9:551-559. doi:10.1038/ $\operatorname{nrd} 3180$

14. Abdul-Ghani MA, Norton L, DeFronzo RA. Renal sodium-glucose cotransporter inhibition in the management of type 2 diabetes mellitus. Am J Physiol Renal Physiol. 2015;309:F889-F900. doi:10.1152/ajprenal.00267.2015
15. Mudaliar S, Polidori D, Zambrowicz B, Henry RR. Sodium-glucose cotransporter inhibitors: effects on renal and intestinal glucose transport: from bench to bedside. Diabetes Care. 2015;38:2344-2353. doi: $10.2337 / \mathrm{dc} 15-0642$

16. Zinman B, Wanner C, Lachin JM, et al. Empagliflozin, cardiovascular outcomes, and mortality in type 2 diabetes. $N$ Engl $J$ Med. 2015;373:2117-2128. doi:10.1056/NEJMoa1504720

17. Nguyen E, Coleman CI, Nair S, Weeda ER. Cost-utility of empagliflozin in patients with type 2 diabetes at high cardiovascular risk. $J$ Diabetes Complications. 2018;32:210-215. doi:10.1016/j.jdiacomp.2017.10.006

18. Kansal A, Reifsnider OS, Proskorovsky I, et al. Cost-effectiveness analysis of empagliflozin treatment in people with type 2 diabetes and established cardiovascular disease in the EMPA-REG OUTCOME trial. Diabet Med. 2019;36:1494-1502. doi:10.1111/dme.14076

19. Gourzoulidis G, Tzanetakos C, Ioannidis I, et al. Cost-effectiveness of empagliflozin for the treatment of patients with type 2 diabetes mellitus at increased cardiovascular risk in Greece. Clin Drug Invest. 2018;38:417-426. doi:10.1007/s40261-018-0620-x

20. Kaku K, Haneda M, Sakamaki H, et al. Cost-effectiveness analysis of empagliflozin in Japan based on results from the Asian subpopulation in the EMPA-REG OUTCOME trial. Clin Ther. 2019;41:2021-2040. doi:10.1016/j.clinthera.2019.07.016

21. Sullivan PW, Ghushchyan VH. EQ-5D scores for diabetes-related comorbidities. Value Health. 2016;19:1002-1008. doi:10.1016/j. jval.2016.05.018

22. Zheng YM. Methodology and empirical study on the economic burden of diabetes mellitus. Tianjin Univ. 2012.

23. Wang HY. Screening strategy and cost-effectiveness analysis by Markov model for persistent albuminuria among high risk population with chronic kidney disease. Zhengzhou Univ. 2015.

24. Xie XQ, Vondeling H. Cost-utility analysis of intensive blood glucose control with metformin versus usual care in overweight type 2 diabetes mellitus patients in Beijing, P.R. China. Value Health. 2008;11:S23-S32. doi:10.1111/j.1524-4733.2008.00363.x

25. Fang Y, Ding XQ, Zhang YH, et al. Acute kidney injury in a Chinese hospitalized population. Blood Purif. 2010;30:120-126. doi:10.1159/ 000319972

26. Chen XB, Tang L, Chen HY, Zhao LY, Hu SL. Assessing the impact of complications on the costs of type 2 diabetes in urban China. Chin J Diabetes. 2003;11:238-241.

27. Zhang TT. The ischemic attack patient's hospitalization expense made and influence factors analysis. Dalian Med Univ. 2010.

28. National Health Commission. China Health Statistics Yearbook (2018). Beijing: Peking Union Medical College Press; 2018.

29. World Health Organization. Choosing interventions that are cost effective (WHO-CHOICE): cost-effectiveness thresholds; 2013. Available from:http://www.who.int/choice/costs/CER_thresholds/en/ index.html. Accessed November 13, 2018.

30. National Bureau of statistics. Statistical communique of the People's Republic of China on 2017 national economic and social development; 2018. Available from: http://www.stats.gov.cn/tjsj/zxfb/ 201802/t20180228_1585631.html. Accessed November 30, 2018.

31. Kansal A, Zheng Y, Proskorovsky I, Krotneva S, Kandaswamy P, Ruffolo A. Modeling cardiovascular outcomes of treatment with empagliflozin in type 2 diabetes based on hard outcomes data. Value Health. 2016;19:A203. doi:10.1016/j.jval.2016.03.1299

32. Rahman W, Solinsky PJ, Munir KM, Lamos EM. Pharmacoeconomic evaluation of sodium-glucose transporter-2 (SGLT2) inhibitors for the treatment of type 2 diabetes. Expert Opin Pharmacother. 2018;9:1-11.

33. Henkhaus LE, Hay JW. Cost effectiveness of empagliflozin/linagliptin as 2 nd-line therapy for adults with type 2 diabetes. Value Health. 2016;19:A202-A203. doi:10.1016/j.jval.2016.03.1297

34. Pawlik D, Wójcik R, Zawodnik A, Kaczor MP. Cost-effectiveness of empagliflozin in patients with type 2 diabetes mellitus at high cardiovascular risk in Poland. Value Health. 2017;20:A478. doi:10.1016/j. jval.2017.08.453 
35. Daacke I, Kandaswamy P, Tebboth A, Kansal A, Reifsnider O. Costeffectiveness of empagliflozin (Jardiance) in the treatment of patients with type 2 diabetes mellitus (T2DM) in the UK based on EMPA-REG outcome data. Value Health. 2016;19:A673. doi:10. 1016/j.jval.2016.09.1876

36. Mettam SR, Bajaj H, Kansal AR, Kandaswamy P. Cost effectiveness of empagliflozin in patients with T2DM and high CV risk in Canada. Value Health. 2016;19:A674. doi:10.1016/j.jval.2016.09.1882

37. Iannazzo S, Mannucci E, Reifsnider O, Maggioni AP. Costeffectiveness analysis of empagliflozin in the treatment of T2D with previous cardiovascular disease in Italy. Value Health. 2017;20: A480-A481. doi:10.1016/j.jval.2017.08.464

38. Oksuz E, Malhan S, Kamaci E, et al. Cost-effectiveness of empagliflozin (Jardiance ${ }^{\circledR}$ ) in the treatment of patients with type 2 diabetes mellitus (T2DM) in Turkey based EMPA-REG outcome data. Value Health. 2017;20:A479. doi:10.1016/j.jval.2017.08.457

39. Aguiar-Ibáñez R, Palencia R, Kandaswamy P, Li L. Cost-effectiveness of empagliflozin (Jardiance ${ }^{\circledR}$ ) $10 \mathrm{mg}$ and $25 \mathrm{mg}$ administered as an add-on to metformin and sulfonilurea (Met+SU) compared to other sodium-glucose co-transporter 2 inhibitors (SGLT2Is) in patients with type 2 diabetes mellitus (T2DM) in the UK. Value Health. 2014;17: A351.

40. Aguiar-Ibáñez R, Palencia R, Kandaswamy P, Li L. Costeffectiveness of empagliflozin (Jardiance ${ }^{\circledR}$ ) $10 \mathrm{mg}$ and $25 \mathrm{mg}$ administered as an add-on to metformin compared to other sodiumglucose co-transporter 2 inhibitors (SGLT2Is) for patients with type 2 diabetes mellitus (T2DM) in the UK. Value Health. 2014;17:A350-1. doi:10.1016/j.jval.2014.08.729

41. Carrasco Perez M, Male N, Serra Burriel M, Pfarr E, Kansal A. Indirect cost-effectiveness analysis of empagliflozin compared to canagliflozin for patients with T2DM and cardiovascular disease in the Spanish National Health Service. Value Health. 2018;21:S130. doi:10.1016/j.jval.2018.09.778
42. Lamotte M, Ramos M, Salem A, et al. Cost-effectiveness analysis of empagliflozin in comparison to liraglutide based on cardiovascular outcome trials. Value Health. 2018;21:S131. doi:10.1016/j.jval.2018.09.781

43. Huicochea-Bartelt JL, Vargas-Valencia JJ, Herran S. Cost-effectiveness (CE) analysis of empagliflozin $25 \mathrm{mg}$ versus sitagliptin $100 \mathrm{mg}$ in the treatment of patients with type 2 diabetes mellitus (T2DM) when added to metformin (MET) from a Mexican public institutional context. Value Health. 2015;18:A61. doi:10.1016/j.jval.2015.03.359

44. Gorgojo-Martínez JJ, Malkin SJP, Martín V, Hallén N, Hunt B. Assessing the cost-effectiveness of a once-weekly GLP-1 analogue versus an SGLT-2 inhibitor in the Spanish setting: once-weekly semaglutide versus empagliflozin. J Med Econ. 2020;23:193-203. doi:10.1080/13696998.2019.1681436

45. Buse JB, Wexler DJ, Tsapas A, et al. 2019 update to: management of hyperglycemia in type 2 diabetes, 2018. A consensus report by the American Diabetes Association (ADA) and the European Association for the Study of Diabetes (EASD). Diabetes Care. 2020;43:487-493. doi:10.2337/dci19-0066

46. Cosentino F, Grant PJ, Aboyans V, et al. 2019 ESC guidelines on diabetes, pre-diabetes, and cardiovascular diseases developed in collaboration with the EASD. Eur Heart J. 2020;41:255-323.

47. Jia W, Weng J, Zhu D, et al. Standards of medical care for type 2 diabetes in China 2019. Diabetes Metab Res Rev. 2019;35:e3158. doi:10.1002/dmrr.3158

Diabetes, Metabolic Syndrome and Obesity: Targets and Therapy

Dovepress

\section{Publish your work in this journal}

Diabetes, Metabolic Syndrome and Obesity: Targets and Therapy is an international, peer-reviewed open-access journal committed to the rapid publication of the latest laboratory and clinical findings in the fields of diabetes, metabolic syndrome and obesity research. Original research, review, case reports, hypothesis formation, expert opinion and commentaries are all considered for publication. The manuscript management system is completely online and includes a very quick and fair peer-review system, which is all easy to use. Visit http://www.dovepress.com/testimonials.php to read real quotes from published authors.

Submit your manuscript here: https://www.dovepress.com/diabetes-metabolic-syndrome-and-obesity-targets-and-therapy-journal 